\title{
Perceived Difficulty of Friendship Maintenance Online: Geographic Factors
}

\author{
Kristie Holmes \\ School of Social Work, Union University, Jackson, USA \\ Email: kristieholmes@gmail.com
}

Received August $17^{\text {th }}, 2012$; revised September $20^{\text {th }}, 2012$; accepted October $3^{\text {rd }}, 2012$

\begin{abstract}
Geographic location has an effect on the perceived ease of friendship maintenance online and may reflect physical space. Participants from the Northeastern United States rated maintaining friendships online as more difficult than those from other regions. Those with the highest anxiety level ratings were from the largest and most densely populated areas (metropolitan) and those who were the least anxious about their image (both online and offline) were from rural areas with the least population density. Those residing in metropolitan areas were the most trusting of online information posted by others and the town/small city group were the least trusting of others' online posted information (similar to the urban group), making those from rural areas nearly as trusting of others' information as the metropolitan group, though probably the result of entirely different influences.
\end{abstract}

Keywords: Social Networking; Friendship; Geography; Relationship; Perceptions; Online

\section{Introduction}

"Whatever may be its present shortcomings and defects, there can be no doubt that wireless telegraphy-even over great distances-has come to stay, and will not only stay, but continue to advance. If it should become possible to transmit waves right round the world, it may be found that the electrical energy travelling round all parts of the globe may be made to concentrate at the antipodes of the sending station. In this way it may some day be possible to send to such distance lands by means of a very small amount of electrical energy, and therefore at a correspondingly small expense."1 (p. 221)

When online relationship maintenance and social networks were not ubiquitous, it was questioned whether the advent of online relationships equated the "end of geography" (Graham, 1998). This researcher wanted to explore the question of whether or not geography played a role in participant perceptions on the ease of friendship maintenance as supported by online networks. In previous work that focused on traditional relationship maintenance as affected by geography, Liben-Nowell, Novak, Kumar, Raghavan, and Tomkins (2005) found that the probability of friendship decreases not only with distance but even more defined by the number of people who lived closer to the participant. Onnela, Arbesman, Gonzales, Barabasi, and Christakis (2011) described geography as a constraint to group formation, in that people form ties through connections of their own friends. Further, they found that geography maintains its power as a way to compartmentalize groups, and referred to Lambiotte's, Blondel, Kerchove, Huens, Prieur, Smoreda and Van Dooren's (2008) study that found that in telephone contact, the duration of a phone call increases with distance. And while phone calls to closer (geographically) friends are more numerous, the farther geographical distance encourages less frequent but longer conversations, demonstrating that even with technology, physical distance indeed has an effect on relationship maintenance. Gilbert, Karahalios, and Sandvig (2010) maintained that "a priori social patterns manifest themselves in social media even when technology could be used to change the patterns" (p. 1383).

Hypothesis 1: Participants from the Northeastern United States will rate maintaining friendships online as more difficult than those from other regions.

The advent of relationship maintenance through online means was met with great expectations that it would completely revolutionize relationships and perhaps even "do away" with physical geography all together. While electronic maintenance has certainly revolutionized a mode of interpersonal connection, surprisingly to many, much remains the same. When specifically investigating geographical influence on behaviors in this paradigm, geography seems to matter in two ways.

First, users "tag" themselves electronically via their smartphone GPS with Facebook, Twitter, Foursquare, or through tagging themselves in photos or by others in location-based social networks or by friends on sites like Facebook in order to share information among their network or "followers," essentially adding a GPS tracking device to oneself. Further, most location-based search terms place a user within miles of the searched geographical space.

Scellato, Mascolo, Musolesi, and Latora (2010) found that users trended toward having short-range social connectedness and that their geographical location was confined to clusters. Backstrom, Sun, and Marlow (2010) realized that even when search queries for places such as the Grand Canyon were analyzed, most searches came from within 50 miles of the actual park

Second, geographic distance, despite the global nature of the internet, still clusters people within distinct geographical boundaries. Technology "... has decreased the importance of geographic proximity in social interactions, transforming our world into a global village with a borderless society. We argue for the opposite: while technology has undoubtedly increased 
the overall level of communication, this increase has been most pronounced for local social ties" (Goldenberg \& Levy, 2009: p. 1). Mok and Wellman and Carrasco (2010) questioned how much distance mattered before the internet, and found that physical distance seems to matter whether or not there was internet, although it has changed how relationships persist over time. For example, friendships that may have stayed snugly in memory as dim high school recollections may now enjoy a repartee online reflective of relationships and habits from the past, when discussing recent news stories or seeking advice on childrearing items. Whether these rekindled relationships are positive, neutral, or negative will of course depend on how much old, renewed, but previously abandoned relationships bump up against the present.

Shaw (2010) discussed the relevance of Hägerstrand's (1970) concept of "bundle" within the context of conceptual restraints, meaning that individuals perform tasks or a specific activity in unison in order to complete an outcome. Shaw updates this concept by linking the notion of online social networks with the linking of physical locations to a virtual one. "We could argue that locations of nodes and links in a virtual network are not relevant according to a topological perspective. This is true only if we are interested in the connectivity and flows between different nodes on social networks" (p. 2). He went on to illustrate by stating that someone who wants to complete a task with a friend who lives 1000 miles away is unlikely to suggest meeting at a local coffee shop.

Recent literature on the geographical location of users of social media is fairly meager, with the same literature reviews pointing to the same handful of studies. However, as supported by Backstrom et al.'s (2010), observations from even the earliest studies have not changed: "the further you get from a person, the lower likelihood you will find her friends there" ( $p$. 3 ). These researchers also found that those who lived in cities were more likely to have friends scattered throughout the country. Gilbert, Karahalios, and Sandvig (2008) found results in a related topic when they found that the strength of relationship ties of urbanites were more loosely defined than those from rural communities, and concluded that rural and urban residents use social media in different ways. Rural participants claimed fewer friends, and those friends were located close to their place of residence. Further, rural participants maintained higher privacy settings than their urban counterparts, revealing a lower level of trust in others. This researcher was interested in the relationship between user location (geographical) and possible differences in perception regarding relationship maintenance online, and found that existing literature was lacking in answers.

Hypothesis 2: Participants from rural areas will be less trusting of others' personal information posted online than those from metropolitan areas.

\section{Social Networking Analysis Theory}

Social network analysis is grounded in the systematic analysis of empirical data, although it was once seen as a method of inquiry rather than a stand-alone theory. People now actively think of their social networks (how and whom they are connected to in real life) the way sociologists have for many decades because of the influence of online social networks such as Facebook and Twitter. These networks have long been researched by sociologists as an acknowledged way to maintain relationships (Keller, 1968) share information, and fit in with those surrounding oneself in a community (Freeman, 2004). The biggest difference in then and now is the ease with which one is included in or isolated from particular networks, and the easier tracking by researchers with an eye for electronic data mining that is now available in numbers that would have been incomprehensible 30 years ago (Butts, 2009). Wellman (2008) stated, "Thirty years ago, I could not even sell the term 'social network' to sociologists" (p. 2).

Granovetter in 1973 defined a tie and its strength as related to an investment of time, emotional intensity, mutual confidence, and reciprocity. Festinger, Schachter, and Back (1950) simplified the idea of propinquity by showing that the term meant that, in the simplest terms, people befriend their neighbors. Festinger's social comparison theory ties in further with how people view themselves (and the contents of one's social networking profile) with regards to their felt perceptions about how others are superior or inferior to themselves.

Still, however, even with all of the data available, it seems that people's networks, although globally available in a way never before imagined, generally support very localized relationships (within driving distance). Rather than "the end of geography" (Graham, 1998) as we know it, at this point it appears that while the availability helps one forge new connections, at its core, electronic social networking in many ways continues to reflect the way things have historically been with relationships online reflecting the connections one has in real time. People continue to make comparisons of themselves in relationship to others in the community. This study explores what this researcher views as simply a newer mode of communication and how participants perceive its role in supporting or taking away from relationships. How close ties are to begin with may play a role, as Gilbert (2012) suggested, in that the perceived ease or difficulty may depend on the intimacy of the relationship in the first place. It was suspected by this researcher that, in the end, while technology changes at a rapid pace as do the options available to communicate, the more intimate the relationship, the more likely the desire to prefer face-to-face interaction. Although technology such as Skype (free online video conferencing software) is easily accessible to most users of social networking technology in their own homes, most people at this point don't prefer to use Skype to communicate "faux face to face" over other electronic means. Takhteyev, Gruzd, and Wellman (2012) stated simply, "Social contacts benefit from physical proximity" (p. 1). Physical geography then, of course, would have an effect on the perceived ease of maintaining relationships via electronic means.

\section{Method}

An online survey was distributed through Facebook via a web-based platform, targeting ages 18 and over (Appendix A). Participants were from 38 states in the United States and 24 participants resided outside of the United States. This sample was heavily Caucasian and well educated. The survey consisted primarily of closed-ended quantitative questions.

Of the 296 participants, 81 identified as male, 209 identified as female, 1 identified as "other", and 5 declined to answer the question. During analysis, the researcher decided to eliminate the responses from the participant who identified with the "other" category in order to restrict the research analysis to two sexes as opposed to three when exploring gender. 
Participants were asked to respond to 28 multiple-choice questions by selecting a single answer they felt best reflected their opinion and 1 open-ended question where they could describe their opinion in their own words with regard to how they view the positive, neutral, or negative effects of technology on their relationships. The survey was designed with a non-optional informed consent agreement, which stated that participants must be age 18 or over to take the survey and made it clear that the survey was completely voluntary and anonymous. The survey included contact information for the Institutional Review Board (IRB) as well as for the researchers so that participants were able to pose questions, comments, or complaints if needed. IP addresses were not collected, and with the exception of the informed consent agreement, every item was voluntary and could be skipped without interrupting the rest of the survey. The snowball sampling technique was used to encourage Facebook users to repost the survey link on their pages to further distribute the survey.

Twitter was used to further disseminate the survey, in addition to professional contact emails that went out to the researcher's network as a separate collector of data. Statistical tests used were independent $t$ tests, ANOVA, Levines, LSD, Bonferonni, and Pplot. Descriptive statistics and chi square were used to analyze results, using (SPSS) IBM 19.0 software. Significance was set at $p=>.05$. However, there were many instances of levels of $p=.06$ or $p=.07$ levels of significance, which this researcher considered as borderline significance in these findings and therefore reportable.

\section{Results}

\section{Geographical Location and Perceived Ease of Friendship Maintenance Online}

Statistical analysis on regional location in the United States and its influence on the perception of friendship maintenance was completed with ANOVA and LSD post hoc testing $(F[4,230]=2.44, p=.04)$ and found that there were significant dif- ferences between regional groups in the United States with designations of West, Southwest, Southeast, Midwest, and Northeast designations.

There was a statistically significant difference between participants from the West with participants from the Midwest (mean difference $-.27, p=.03$ ) as well as the West from the Northeast (mean difference $-.40, p=.04$ ) with participants from Western states finding it easier to maintain friendships online.

There was a statistically significant difference between participants from the Southwest with participants from the Midwest (mean difference $-.80, p=.04$ ) as well as the Southwest from the Northeast (mean difference $-.93, p=.02$ ) and a statistically significant difference between Midwestern state participants (mean difference $=.27, p=.03$ ) and Northeast participants (mean difference $=.38, p=.04$ ). Finally, Northeastern participants had a statistically significant difference between those from the West (mean difference $=.20, p=.04$ ) and the Southwest (mean difference $.41, p=.02$ ).

The range of ease of maintaining a friendship online was 1 (easier) to 3 (harder). The Western states $M$ was 1.72 , Southwest $M$ was 1.20 , Southeast $M$ was 1.85 , Midwest $M$ was 2.13 and the Northeast $M$ was 2.13, making the Midwest and northeast the groups to find maintaining their friendships online the most difficult. However, the neutral option with the range of 2 maintains that maintaining friendships online and in person is the same level of difficulty as maintaining a face-to-face friendship.

\section{Metropolitan, Urban, Town and Rural Residency}

When exploring basic descriptive statistics, ratings for levels of anxiety related to image maintenance (both online and offline) are higher in areas considered metropolitan $(M=4.5)$ with similar ratings from those who reside in urban areas or small cities and town in the middle with $(M=4.41$ to 4.47$)$. Those who reported living in a rural area had a mean rating of 3.95 for anxiety related to image (Figure 1).

When an ANOVA was run on Metropolitan, Urban, Town, and Rural Residency groups according to their level of trust in what other people post online, there was a statistical significance. ANOVA was run along with LSD and Bonferonni post hoc tests $(F[3,266]=4.59 ; p=.004)$ with borderline statistical significant difference between the Rural Group (We are lucky to have a stoplight!) and Town/Small City Group (We have a restaurant chain or two) (mean difference $=.28, p=.004$ ) as well as the Urban (mean difference $=-.30, p=.003$ ). The range of trust rating was 1 (low) to 4 (high). The Metropolitan group mean was 3.25 , the Urban group mean was 3.15 , the Town/Small City group mean was 2.84 and the Rural group mean was 3.12 , thus making the least trusting group, the Town/Small City group, the most trusting of others' online posted information, and those in metropolitan areas most trusting of online information posted by others (see Figure 2).

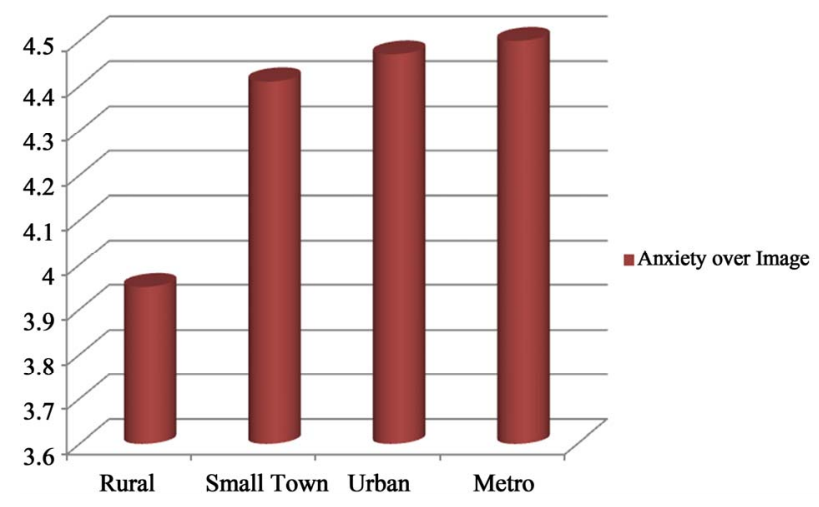

Figure 1.

Anxiety over image.

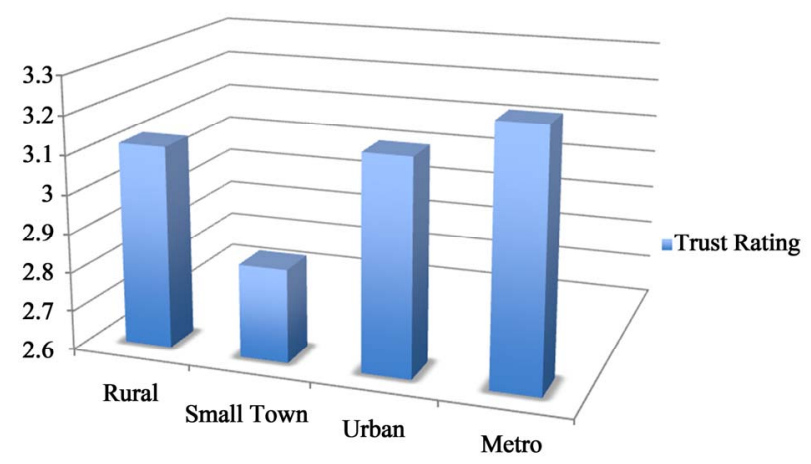

Figure 2.

Trust of information posted online. 


\section{Rural- We are lucky to have a stoplight!}

\section{Town/Small City- We have a restaurant chain or two.}

Urban area- 50K or more people (Mall, large chain stores and restaurants)

Metropolitan area- Usually over a million people (size examples: Los Angeles, NYC, Atlanta, Chicago, Seattle)

Figure 3.

Participant Choices for Population Density.

\section{Discussion}

As theorized by Hypothesis 1, participants from the Northeastern United States rated maintaining friendships online as more difficult than those from other regions. Geographical location seems to affect the perceived ease of friendship maintenance online and may reflect the areas' small physical space (small states in a clustered area). In this region of the United States, driving across multiple state lines in a single day would not be difficult. Perhaps physical geographic boundaries on a smaller space affects one's perception of distance, or even need to maintain relationships online. According to the literature thus far, most participant networks are within driving miles of their location.

Further, the type of environment one resides in has an effect on how participants perceive their image as viewed by others. Those with the highest anxiety level ratings are from the largest and most densely populated areas (metropolitan), and those who were the least anxious about their image (both online and offline) were from rural areas with the least population density (Figure 3).

As for Hypothesis 2, when analyzing trust levels of what other people post online, the borders were not quite as clear. Those residing in metropolitan areas were the most trusting of online information posted by others and the Town/Small City group were the least trusting of others' online posted information (similar to the Urban group), making those from rural areas nearly as trusting of others' information as the metropolitan group. These trust levels may be the result of entirely different influences, with those in metropolitan areas more likely to rely on technology day in and day out and may generally be more trusting of electronic social networks as a source of information. On the other end of the spectrum, those in rural areas may be more generally trusting of others due to the experience of residing in communities that broker more trust due to their physical proximity.

\section{Acknowledgements}

Much thanks to Macy Alligood and Elizabeth Wilson for their time and assistance with this study.

\section{REFERENCES}

Backstorm, L., Sun, E., \& Marlow, C. (2010). Find me if you can: Improving geographical prediction with social and spatial proximity. International World Wide Web Conference Committee 2010 (pp. 61-70). New York: ACM.

Butts, C. T. (2009). Revisiting the foundations of social network analy- sis. Science, 325, 414-416.

Festinger, L., Schachter, S., \& Back, K. (1950) Social pressures in informal groups: A study of human factors in housing. Stanford, CA: Stanford University.

Freeman, L. (2004) The development of social network analysis: A study in the sociology of science. Vancouver: Empirical Press.

Gilbert, E., Karahalios, K., \& Sandvig, C. (2010). The network in the garden: Designing social media for rural life. American Behavioral Scientist, 53, 1367-1388. doi:10.1177/0002764210361690

Gilbert, E., Karahalios, K., \& Sandvig, C. (2008). The network in the garden. An empirical analysis of social media in rural life. Speech Communication, 53, 1603-1612.

Gilbert, E. (2012). Predicting tie strength in a new medium. Proceedings of the ACM 2012 Conference on Computer Supported Cooperative Work (pp. 1047-1056). New York: ACM. doi:10.1145/2145204.2145360

Goldenberg, J., \& Levy, M. (2009). Distance is not dead: Social interaction and geographical distance in the internet era. Computers and Society, 2, 1-22.

Graham, S. (1988). The end of geography or the explosion of place? Conceptualizing space, place and information technology. Progress in Human Geography, 22, 165-185. doi:10.1191/030913298671334137

Granovetter, M. S. (1973). The strength of weak ties. The American Journal of Sociology, 78, 1360-1380. doi:10.1086/225469

Keller, S. (1968). The urban neighborhood. New York: Random House.

Lambiotte, R., Blondel, V., Kerchove, C. D., et al. (2008). Geographical dispersal of mobile communication networks. Physica A, 387, 5317 -5325. doi:10.1016/j.physa.2008.05.014

Liben-Nowell, D., Novak, J., Kumar, R., Raghavan, P., \& Tomkins, A. (2005). Geographic routing in social networks. Proceedings of the National Academy of Sciences of the United States of America, 102, 11623-11628. doi: 10.1073/pnas.0503018102

Mok, D., Wellman, B., \& Carrasco, J. A. (2010). Does distance still matter in the age of the internet? Urban Studies , 47, 2747-2783.

Nan, L., \& Guanling, C. (2009). Analysis of a location-based social network. IEEE International conference on Computational Science and Engineering, 4, 263-270.

Onnela, J., Arbesman, S., González, M. et al. (2011). Geographic constraints on social network groups. PLOS ONE, 6, 1-7. doi:10.1371/journal.pone.0016939

Scellato, S., Mascolo, C., Musolsi, M., \& Latora, V. (2010). Distance matters: Geo-social metrics for online social networks. Proceedings of the 3rd Conference on Online Social Networks. Berkeley, CA: USENIX Association

Shaw, S. (2010). Relevance of time geography to spatio-temporal constraints on social networks. Specialist Meeting-Spatio Temporal Constraints on Social Networks, 1-3.

Takhteyev, Y., Gruzd, A., \& Wellman, B. (2012). Geography of twitter networks. Social networks. Space and Networks, 34, 73-81.

Wellman, B. (2008). The development of social network analysis: A study in the sociology of science. Contemporary Sociology: A Journal of Reviews, 37, 221-222. 